\title{
Egyptian Fractions and Representation Registers in the Construction of the Fraction Concept
}

\author{
Francisco Clemente ${ }^{1 *}$, Josep Maria Fortuny ${ }^{1}$ \\ ${ }^{1}$ Departament de Didàctica de la Matemàtica i de les Ciències Experimentals, Universitat Autònoma de Barcelona, SPAIN \\ Received 8 February 2021 - Accepted 30 May 2021
}

\begin{abstract}
In this work we will analyze the relation between registers of representation and the construction of the fraction concept. Ninety-six students from first year of compulsory secondary education participated in the study, and performed equal share tasks in the context of Egyptian fractions (unit fractions with different denominators). The aim was to determine if, with these types of tasks, students could improve their learning of the different meanings of the fraction concept. Our results indicate that there seems to be a relationship between the meaning used and the representation chosen. Similarly, we found that-with these tasks-students significantly increased the number of registers of representation they used. Students who used distinct representations had to coordinate several registers, which might be interpreted as proof of the development of conceptual understanding.
\end{abstract}

Keywords: Egyptian fractions, fractions, rational numbers, registers of representation, share

\section{INTRODUCTION}

Diverse research projects have highlighted the difficulties students have at learning fractions (Lamon, 2020; Simon et al., 2018). These difficulties usually result from a lack of conceptual comprehension, in which fractions are seen by many students as senseless symbols (Fazio \& Siegler, 2011). These results suggest that a conceptual understanding of fractions raises a critical challenge for students (Wilkins \& Norton, 2018).

In mathematics, the conceptual assimilation of an object necessarily involves the acquisition of several semiotic representations (D'Amore, 2013). Duval (1993) distinguishes between mathematical objects and their representations and claims that representations play an essential role in comprehending the mathematical object (concept). Each mathematical object has several registers of representation which are limited in their meaning and treatment; for this reason, it is essential to mobilize several registers in mathematical activity and to be capable of choosing one register instead of another. That is, Duval underscores the need to coordinate the different registers of representation in order to achieve comprehension of the mathematical object.

\section{Representation of a Fraction}

A mathematical register is a set of meanings with which the discourse on mathematical ideas, objects and processes can be developed (Halliday, 1975). The native language and the mathematical language can coexist in the mathematical register; therefore, mathematics can be projected through many natural languages (Pimm, 2002).

In the case of fractions, some studies show that learning with various representations supports students' conceptual knowledge (Lamon, 2020; Liu, Xin, \& Li, 2011; Zhang, Clements, \& Ellerton, 2014). On the contrary, a single representation may be an obstacle to students' comprehension; for example, the representation of a fraction as an area by drawing a figure partitioned into parts can hinder students' comprehension of improper fractions, since the numerator is higher than the number of partitions of a single figure (Charalambous, Delaney, Hsu \& Mesa, 2010).

It is difficult for many students to discriminate between a numerical set and its registers of representation. This is true with rational numbers, which have equivalent registers of representation. The most common representations used to show a fraction can be

(c) 2021 by the authors; licensee Modestum. This article is an open access article distributed under the terms and conditions of the Creative Commons Attribution License (http://creativecommons.org/licenses/by/4.0/). 


\section{Contribution to the literature}

- In this study we designed equal sharing activities in the context of Egyptian fractions, with the aim of verifying to what extent the different representations of the fraction indicate the knowledge that the students possess about its possible meanings.

- This research shows that the hieroglyphic representation of Egyptian fractions has both graphic and symbolic properties, and could facilitate the transition between them.

- The findings of this research show an increase in the use of registers of representation by students, which could be interpreted as an improvement in the conceptual understanding of fractions.

$$
\begin{array}{ll}
\bigotimes_{\|=\frac{1}{3}} & \bigotimes_{\|\|}=\frac{1}{5} \\
\bigcap_{1}=\frac{1}{21} & \rho_{\|}=\frac{1}{102}
\end{array}
$$

(a)

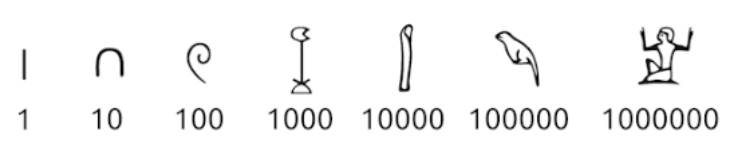

(b)

Figure 1. Egyptian fractions in hieroglyphic representation with their equivalence in modern interpretation with fractional numbers (a) and numeration symbols (b)

classified into graphic and symbolic. Below we provide some examples of each of these representations.

i) Graphic representation: area (rectangle, circle or other figure partitioned into equal parts), longitude (divisions on a numerical line), set of discrete objects.

ii) Symbolic representation: fractional number (3/4). Since these are equivalent numerical registers of representation, we can also represent a fraction as: decimal number $(0.75)$, percentage $(75 \%)$

\section{Egyptian Fractions}

Egyptian fractions establish a representation system with which incomplete positive quantities are expressed (Kaput, 1987). Some authors maintain that fractions were founded in Ancient Egypt within the context of sharing (Fauvel \& Gray, 1987), characterised by the use of unit fractions, in other words, with a unit in the numerator. Attempts have been made from different approaches to explain the meaning of fractions for the ancient Egyptians and the reason for using unit fractions. The fraction can be interpreted with ordinal meaning (Pimm, 2014), as the designation of one of the parts into which the unit is divided. With this interpretation, the fifth part is the last part which is combined with the other four parts to complete the unit. For the Egyptian mind, it would not make sense to talk about two fifths, because in a series of five only one part can be the fifth, that which occupies the last place. In the hieroglyphic representation of these fractions there is a drawing (it possibly represents a "mouth" or a "unit" of food) and below a whole number $n$ to represent the reciprocal of $n$. This could be interpreted as a ration of food which is shared between $\mathrm{n}$ people. The Egyptians wrote unit fractions as shown in Figure 1.

From this perspective, we can admit that hieroglyphic representation is situated between graphic and symbolic representations, since it has properties of both. In other words, the whole (continuous and discrete) known as a unit is represented with the drawing (graphic representation) of a mouth that corresponds to the ration of food; and underneath there is a number (symbolic representation) expressed in the hieroglyphic numeration system that counts the number of people among whom this ration is divided.

With our current mathematical knowledge, we can think of equal sharing as a division. Some authors propose that Egyptian fractions are associated with solving equal shares by successive approaches (Eves, 1969; Furinghetti \& Radford, 2002). According to this hypothesis, for example, the distribution of two loaves of bread between five people would be as follows.

We cannot give a whole loaf of bread to each of the five people. Therefore, each of the loaves must be divided into an integer of equal parts so that we can give one of these parts to each person. In the first approach we can divide each loaf into two equal parts, obtaining four parts, which will not be sufficient. In the second approach, we divide each loaf into three parts, obtaining six parts, and we can give one of these parts to each of the five people, with one part left over. In a second phase, the leftover part can be in turn divided into five parts and we can give one of these parts to each person. With this approach, the distribution of two loaves of bread between five people would take place with successive approaches, expressed with current symbolic representation as shown in Figure 2.

This result coincides with the decomposing fractions into the sum of unit fractions with different denominators that appear on the Rhind papyrus, written between 1650 and 1550 BC (MacGregor, 2011; NRICH, 2020).

Furthermore, the research literature describes the strategies children use to attempt share tasks, for 


$$
2 \div 5=\frac{1}{3}+\frac{\frac{1}{3}}{5}=\frac{1}{3}+\frac{1}{15}
$$

(a)

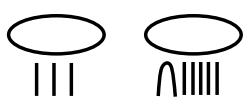

(b)

Figure 2. Equal sharing (division) of two loaves of bread among five people with a symbolic register of representation in a fraction, and broken down into unit fractions (a), and hieroglyphic register of representation in Egyptian fractions (b)

example, sharing three pizzas between five people or similar tasks (Clarke, Roche, \& Mitchell, 2011). These strategies include the procedure of successive trial and error approaches, performing divisions between powers of two: dividing each pizza by half and dividing all the parts, then verifying if there are enough portions and if there are any leftover portions, dividing the leftover part into quarters, repeating the procedure with eighths if there are not enough portions or if the quarters leave leftovers (Pothier \& Sawada, 1983). In other cases, the children performed the successive trial and error approaches by division with integers: dividing each pizza by half six portions were obtained and five of them could be distributed among the people; then, the remaining half was divided into five parts again and these were distributed. In the end, each of the five people obtained one half and one tenth. In other words, some children performed the distribution of three pizzas among five people with successive approaches, as follows:

$$
3 \div 5=\frac{1}{2}+\frac{\frac{1}{2}}{5}=\frac{1}{2}+\frac{1}{10}
$$

There is a large quantity of literature on the thinking of students about fractions (Ball, 1993; Cramer et al., 2019; Lamon, 2007, 2020; Tzur, 1999). However, Egyptian fractions are rarely used in teaching and there is little related curricular material (Kosheleva \& Lyublinskaya, 2007). Some simple activities are described in the literature, in which Egyptian fractions have been successfully used in middle school grades (Bentley, 2004; Oliver, 2003; O'Reilly, 1995). Despite the fact that this subject is overlooked, Lingard (1999) considers that the use of unit fractions by the early Egyptians is a subject worth exploring, with well-documented historical references, which would help many students to learn fractions. Along the same lines, Cramer, Post, and delMas (2002), describe an activity which used ancient Egyptian methods to calculate with unit fractions, highlighting the importance of providing students with an instruction which involves multiple representations in order to help them to develop the concepts of rational numbers.

\section{Meanings of the Fraction Concept}

For some authors, a factor that hinders the learning of fractions is related to their different meanings (Behr et al., 1992; Kieren, 1993; Lamon, 2020). For example, for the fraction concept $3 / 4$ we can identify five subconstructs:
- Quotient: three divided by four. It allows equal shares between different magnitudes, for example, partitioning three objects in equal parts between four people.

- Operator: three quarters of a quantity. A quantity is multiplied by the numerator (three) and is divided by the denominator (four).

- Measure: the submultiple $1 / 4$ of the unit is repeated three times (one point on the numerical scale).

- Ratio: three to four. Relation between magnitudes, it serves to compare quantities of magnitudes.

- Part-whole: three of four equal parts. The whole (continuous or discrete) called a unit is divided into four equal parts, three of which are considered.

Therefore, the same register of representation allows for distinct meanings of the mathematical object represented. Furthermore, certain aspects of the same concept may be facilitated or hindered by a given meaning; for example, the meaning of the fraction as a part-whole ratio hinders an understanding of fractions larger than one. On the other hand, a given register of representation also facilitates or hinders certain aspects of the mathematical concept; for example, comparison of the fractions $3 / 5$ and 5/8 may not be immediate comprehensible, whereas a comparison of their respective decimal expressions, that is, 0.6 and 0.625 , are more readily understandable.

For Freudenthal (1983), the phenomenological characteristics of these meanings are reflected at the cognitive level, manifesting themselves as conditioning factors in students' understanding of the fraction.

The notion of fraction is frequently introduced through the part-whole subconstruct (Lamon, 2020), which requires the capacity to divide a continuous quantity or a set of discrete objects (unit) into equal parts or subsets. Students must realise that the relation between the parts and the set is maintained, regardless of the size, form and disposition (Pantziara \& Philippou, 2012). The part-whole subconstruct is deemed essential for developing the comprehension of the other four subconstructs (Kieren, 1993).

The ancient Egyptians represented unit fractions as parts of the whole; they did not consider a fractional quantity to be a different number on a par with whole or natural numbers (Berlinghoff \& Gouvea, 2004). This historical development is similar to the difficulties of students concerning the fraction concept, since at present 
the part-whole meaning is an approach often used by teachers and does not support the consideration of the fraction as a number (Lamon, 2007). Understanding fractions as numbers is not trivial either for the mathematicians of the past or for the students of the present (Park, Güçler, \& McCrory, 2013).

Bearing in mind the characteristics of the different representations and of the possible meanings of the fraction concept in the equal sharing tasks, we consider the following research question:

- To what extent do activities with Egyptian fractions improve the conceptual understanding of the students?

\section{THEORETICAL FRAMEWORK}

The study we are presenting takes as its perspective the theory of registers of semiotic representation proposed by Duval (1993). Duval claims that mathematical objects are not accessible to perception and therefore must be represented. Similarly, he distinguishes between mental representation, meaning a set of images and conceptualizations that an individual may have about an object or situation, and semiotic representation, which is a set of signs that allow individuals to communicate mental representations and produce new knowledge.

According to this theory, using systems of semiotic representation is essential to mathematical thinking, such representations are the only way of accessing mathematical objects. Furthermore, Duval claims that every register of semiotic representation is cognitively partial with regard to the object represented; that is, no representations of mathematical objects are complete, and all of them highlight certain aspects of an object while obscuring others. For this reason, being able to activate several distinct registers and choose one register over another is fundamental in mathematical activity (Duval, 2006).

Duval (2000) indicates that a register of representation should allow for the three cognitive activities inherent to any representation: formation, treatment and conversion.

Formation consists of identifying a representation in a given register. The other two activities are related to transforming representations into other representations.

Treatment is the internal transformation of a register, and there are rules inherent to each register. To Duval (2006), the essential role of the numerical system of representation is not to represent numbers but to calculate, and the algorithms used are distinct according to the semiotic register of representation used. Semiotic systems are primarily used for operations, that is, for treatment.

Conversion is an external transformation of a register; it consists of exchanging registers while keeping the same mathematical object, as when exchanging a graphic register for a symbolic register.

The cognitive complexity of conversion is largely due to the fact that changing the representation of mathematical objects from one semiotic system to another always represents a cognitive leap. For Duval, there is no conceptual apprehension (noesis) without coordination between registers (semiosis). From this perspective, the conversion would be an essential condition for conceptual understanding and any problem with the conversion would indicate erroneous concepts.

To properly coordinate the distinct registers of representation, the conversion must be easy to carry out for all the possible changes in register. This coordination can be fostered by tasks that allow students to methodically explore the possible changes of a representation in a given register, as well as by predicting similar changes in the representation in the other register. For this reason, teaching mathematics cannot be limited to simply presenting several examples of conversion. In this sense, we can state that mathematical comprehension will depend upon the student's ability to recognize the register of representation pertaining to a mathematical object (formation), and then use it (treatment) and change it (conversion).

Mathematical comprehension requires internal coordination among all the possible systems of semiotic representation that can be selected and applied. The skill of simultaneously mobilizing distinct representations depends on the development of this coordination, and conceptual understanding stems from carrying this through; in contrast, a lack of coordination among these systems of semiotic representation leads to difficulties of comprehension (Duval, 2000).

\section{METHODOLOGY}

\section{Context and Tasks}

Ninety-six students from first year of compulsory secondary education (between 12 and 13 years of age) in a public education centre took part in this study. According to the national curriculum, it is necessary for pupils to know the meanings of fractions in different contexts and their origin and use in antiquity. A teaching experiment was designed which was incorporated into the subject of Mathematics, with the aim of studying if students could improve the construction of the fraction concept by performing equal share activities in the context of Egyptian fractions. Previously, they had studied different numbering systems including that of ancient Egypt and its use of fractions. 
Table 1. Tasks the students had to solve in each of the phases

\begin{tabular}{|c|c|}
\hline $\begin{array}{l}\text { Exploration } \\
\text { phase }\end{array}$ & $\begin{array}{l}\text { 1. Let's be archaeologists! } \\
\text { A papyrus written in hieroglyphic language has been found in an } \\
\text { Egyptian temple. It says: "To distribute three bags of wheat } \\
\text { between four people we will do as follows:" } \\
\text { Explain how you would carry out the distribution. What do these } \\
\text { strange drawings mean? }\end{array}$ \\
\hline $\begin{array}{l}\text { Phase of } \\
\text { applying new } \\
\text { knowledge }\end{array}$ & $\begin{array}{l}\text { 2. Now let's be scribes! } \\
\text { a) The pharaoh asks us to distribute } 5 \text { bags of wheat between } 12 \text { people. Expl } \\
\text { out the distribution and express it with Egyptian fractions. } \\
\text { b) And if we had to distribute } 7 \text { bags between } 20 \text { people, explain how you wo } \\
\text { distribution and express it with Egyptian fractions. }\end{array}$ \\
\hline $\begin{array}{l}\text { Phase of } \\
\text { reconstructing } \\
\text { the unit }\end{array}$ & $\begin{array}{l}\text { 3. The Eye of Horus } \\
\text { According to Egyptian mythology, Horus fought his uncle Seth. In } \\
\text { the fight his left eye was injured and divided into the six fractions } \\
\text { in the drawing. Do you think that Horus' eye can really be } \\
\text { completed by uniting the six fractions of the eye? Justify your } \\
\text { answer and explain how you think it could be completely } \\
\text { reconstructed. }\end{array}$ \\
\hline
\end{tabular}

\section{Instruments}

As part of the evaluation of the teaching experiment, the students were asked to perform a series of written tasks (Table 1) based on three phases and carried out in two sessions of one hour each:

- Session 1: Presentation of the tasks and exploration phase.

- Session 2: Application of new knowledge phase and unit reconstruction phase.

These tasks were designed considering the learning trajectory in order to recognize the effects of the sequence of tasks on the progression of the conceptual apprehension of the students. The possible meanings of the fraction were considered (Behr, Harel, Post \& Lesh, 1992), in addition to its different representations, which were studied from the perspective of the model of registers of semiotic representation (Duval, 1993).

The development sequence and learning goals according to the possible strategies and representations that could be used by the students are shown below.

i) In the exploration phase students were asked to perform a task in which something was divided equally (divide three bags equally between four people) and to relate their response to the Egyptian fractions shown in the problem, that is, to recognize the register of representation through an activity involving formation. To carry out this task, students were expected to use the different subconstructs of the concept of fraction and indicate their solution with a single register of representation. The cognitive demand was low and we expected to find mostly representations with individual characteristics of each student, without connections between the one they have generated themselves and the hieroglyphic representation shown in the statement.

ii) The applying-new-knowledge phase was to be carried out after students shared their proposed solutions to the previous activity with the whole group. Similar to the previous activity, in this phase the students also had to divide something equally into two parts ( $a$ and $b$ ). They were also expected to recognize (formation activity) and express the solution to this distribution problem in Egyptian fractions via a change in register (conversion activity). To distribute 5 bags of wheat to 12 people (a); and 7 bags of wheat to 20 people (b); they could use the subconstructs of the fraction concept and the representations described in the previous activity. The students were expected to form the fractions $\frac{5}{12}$ and $\frac{7}{20}$ as the sum of unit fractions with a different denominator, for example:

a. $\frac{5}{12}=\frac{1}{3}+\frac{1}{12}$; or, other alternatives: $\frac{5}{12}=\frac{1}{4}+\frac{1}{6}$; $\frac{5}{12}=\frac{1}{4}+\frac{1}{8}+\frac{1}{24}$

b. $\frac{7}{20}=\frac{1}{4}+\frac{1}{10}$; or, other alternatives: $\frac{7}{20}=\frac{1}{3}+\frac{1}{60}$; $\frac{7}{20}=\frac{1}{5}+\frac{1}{10}+\frac{1}{20}$

The cognitive demand was medium and we expected to find mostly representations with graphical registers and heuristic strategy to find the solution of the problem by non-rigorous methods, such as trial and error, as well as with connections that relate the student's representation to the hieroglyphic. Moreover, we expected some students to start the shift to the higher level of cognitive demand through a generalized representation, which would enable them to deduce that any fractional number can be expressed as the sum of unit fractions with different denominators, and that this breakdown is not unique.

iii) In the phase of reconstructing the unit the students had to imagine a "whole" using different fractions. The exercise consisted of checking if the sum of the fractions that appeared in the problem made up the unit and, if this were not the case, suggest how the unit could be obtained. In this task it was expected that, either using symbolic representation with fractional numbers, or 


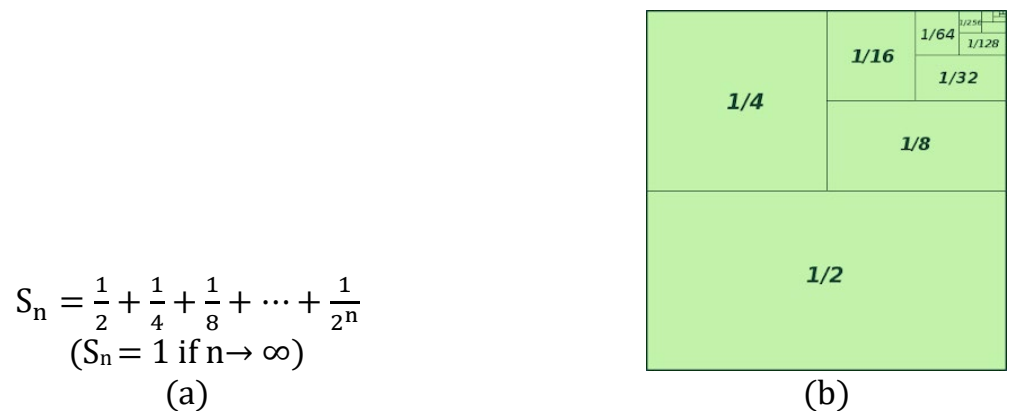

Figure 3. Sum of infinite different unit fractions with which the unit is obtained, using symbolic representation with fractional numbers (a); and with graphic-area representation (b)

using graphic-area representation, the students could indicate that the Eye of Horus could not be completed with the sum, since the result was different from the unit and explain how it could be completed.

If they added the fractions, they had to verify that 1/64 needed to be added to complete the Eye of Horus. But, by adding 1/64 there would be two equal fractions, with the inconvenience that Egyptian fractions require different unit fractions. The cognitive demand was high, although it is unlikely that students of this age would find this alternative, the Eye of Horus could be completed (obtain the unit) with Egyptian fractions, adding an infinite number of different unit fractions (sum of the terms of a geometric ratio progression $r$ $=1 / 2$ ), with symbolic or graphic representation (Figure $3)$.

\section{Data Analysis}

The data of this research are the students' responses to the three tasks that they had to solve, in which we study, starting from the different representations and possible meanings of the fraction, the formation, treatment and conversion activities (Duval, 1993). The data as a whole are considered in the analysis; the individual learning pathways are not analyzed. This aggregate analysis was performed as an initial approach of this line of research focused on activities which favour coordination between different registers of representation, with the aim of studying the possible improvement in the conceptual understanding of the students.

i) In the exploration phase, the responses were classified according to the subconstructs of the fraction concept used in the solutions, the representations used and whether or not the students were capable of relating their solution with Egyptian fractions. Starting from the above information we identified:

- Evidence that in their solution of the equal share, the students used one of the previously described subconstructs: quotient, operator, measure, ratio, part-whole (direct or with successive approaches).

- The representations they used to make use of the subconstructs: graphic (area, longitude, set) and symbolic (fractional number, decimal number, percentage).

- If the hieroglyphic representation (problem data) changed to symbolic or graphic representation (depending on their solution) and if they related their solution with Egyptian fractions, interpreting them as a solution to the problem.

The classification of the students' responses in accordance with the subconstructs and representations of the fraction concept used; and the change of hieroglyphic representation to symbolic or graphic representation has taken place and, additionally, if there is evidence of the student relating his/her response with Egyptian fractions and interpreting them as a solution to the problem.

In the responses from the exploration phase we found the following cases which we illustrate with analysis examples:

a) Distribution through the use of one single subconstruct and one single representation (Figure 4): the case of Martina.

The case of Martina. Use of the part-whole subconstruct with successive approaches: in the first approach she divides each bag into two equal parts, obtaining six parts, giving one of these parts to each of the four people, with two parts left over. Then, she divides the two leftover parts into another two parts, obtaining four portions and gives one of these to each person. She uses the graphic-area representation (rectangles); in addition, the student draws the four people who receive a portion, identifying them with upper case letters (A, B, C and D) and relates them with the portions from the bags which she also assigns letters that correspond to each of the people. She performs cognitive activities of formation, treatment and conversion. She changes the hieroglyphic representation to a symbolic representation with a fractional number, she relates her solution with Egyptian fractions using arrows and interprets them as a solution to the problem expressing it with the text: " $1 / 21 / 4(\ldots)$ is the amount for each of the people". Similarly, she checks that the Egyptian fractions correspond with the breakdown of the fraction $3 / 4$ in the sum of unit fractions: $1 / 2+1 / 4=3 / 4$. 


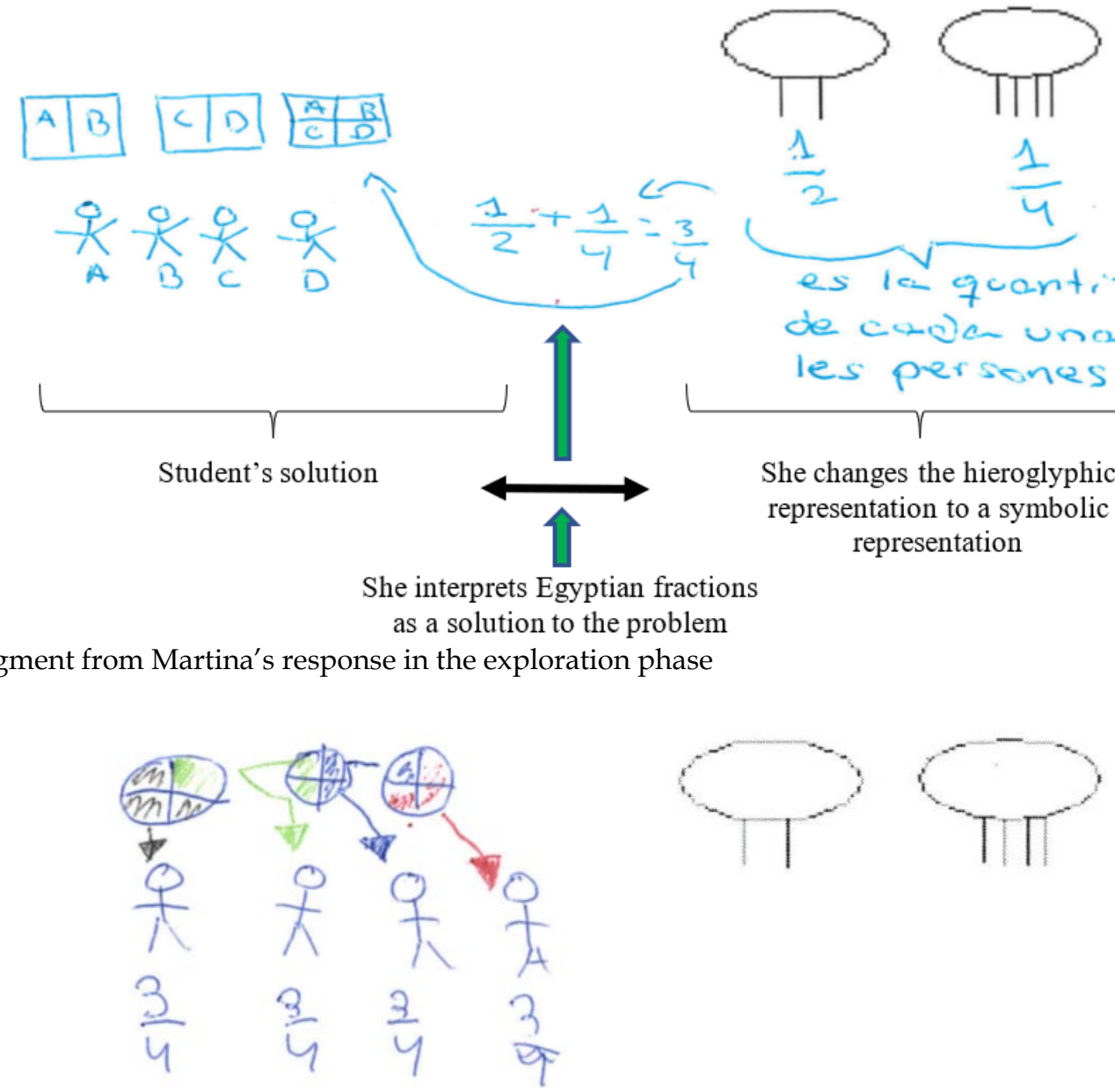

Figure 5. Fragment from Marc's response in the exploration phase
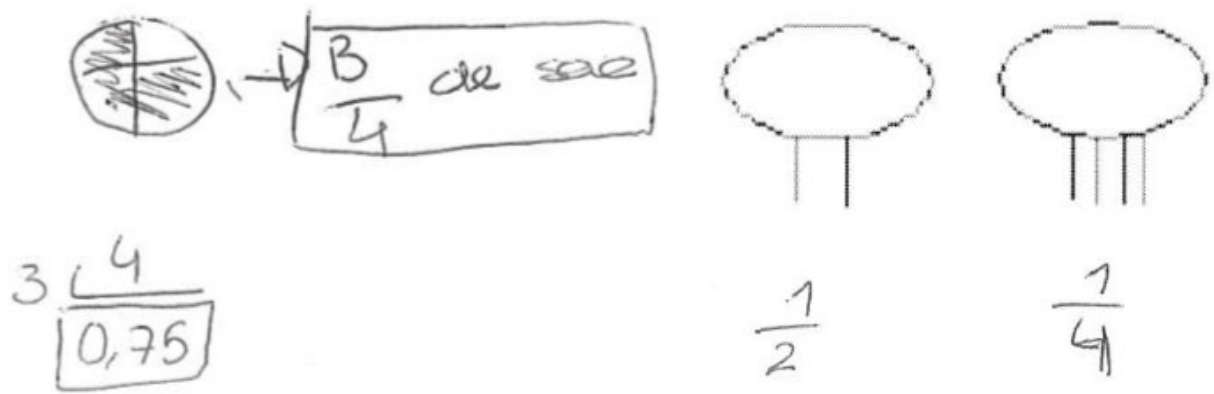

Figure 6. Fragment from Txell's response in the exploration phase

b) Use of one single subconstruct and various representations (Figure 5): the case of Marc.

The case of Marc. Use of the direct part-whole subconstruct: he divides each bag into four equal portions and gives three of them to each of the four people. He uses two representations, the first is graphicarea (circles) and the second is symbolic with a fractional number. In the first representation, the student draws the portions of the bags (circular sectors of $90^{\circ}$ ) which correspond to each of the four people, identifying them with colours; that is, he assigns a different colour to each person receiving a portion. Additionally, he draws the four people and relates them to the portions of the bags using arrows with the corresponding colours. As he solves the division, he carries out a conversion by changing from graphic-area register to symbolic-fraction register (situated beneath the drawing of each person). He performs the cognitive activities of formation and conversion. He does not change the hieroglyphic representation to a symbolic or graphic representation and does not interpret Egyptian fractions as a solution to the problem.

c) Use of diverse subconstructs and various representations (Figure 6): the case of Txell.

The case of Txell. Use two subconstructs:

Subconstruct 1 . She uses the operator subconstruct: she takes three quarters of a bag. She uses two representations, with a graphic-area register (circle), and she switches to a symbolic-fraction register using a 


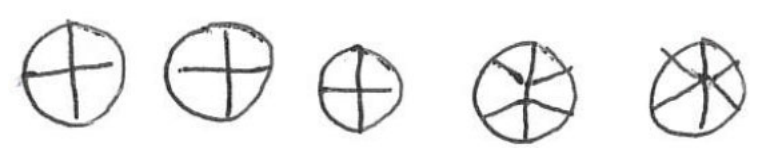

Figure 7. Fragment from Eric's response in the phase of applying the new knowledge

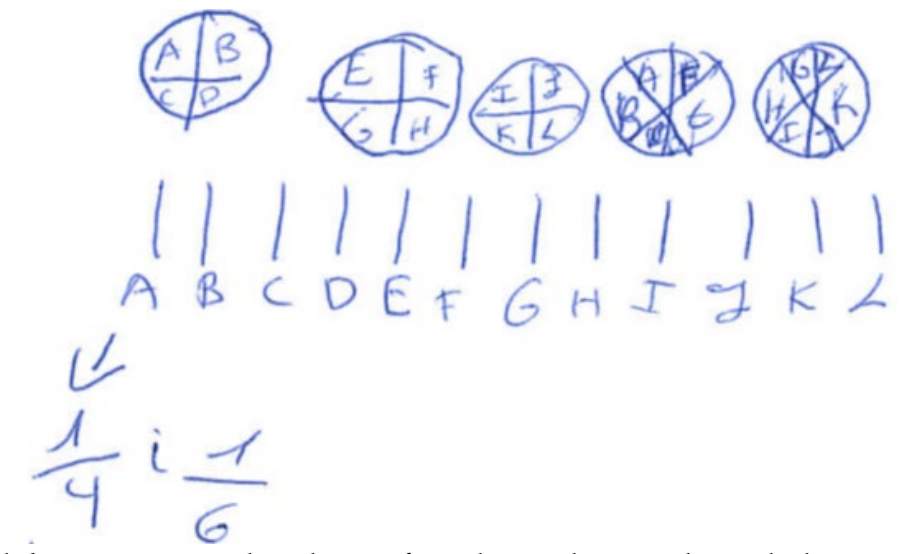

Figure 8. Fragment from Paula's response in the phase of applying the new knowledge

conversion. For the first representation, the student colours the three portions of the bag that she takes from the four that she has drawn (circular sectors of $90^{\circ}$ ). In the second representation, she uses a fractional number accompanied by a text: "3/4 of a bag". She establishes a relation between the graphic representation and the symbolic representation, joining them with an arrow.

Subconstruct 2. She uses the quotient subconstruct: using the algorithm of division she divides three bags between four people. She uses the symbolic representation with a decimal number to express the result. She changes the hieroglyphic representation to a symbolic representation with a fractional number, but she does not relate her response with Egyptian fractions or interpret them as a solution to the problem. She performs the cognitive activities of formation, treatment and conversion.

ii) The phase of applying the new knowledge took place after pooling the different solutions put forward by the students for the previous activity. The responses were classified according to the subconstructs of the fraction concept used, the representations used and the methods employed by the students to break down each fraction into a sum of unit fractions with different denominators (Egyptian fractions). Similar to that performed in activity 1 , we identified evidence that students used some of the subconstructs in their equal-sharing problem, as well as the representations they used.

In the responses of the phase of applying the new knowledge, we found that just a single subconstruct was used in the divisions, namely, part-whole with successive steps. We classified the solutions according to whether students used one, two or three registers of representation, which we illustrate with analysis examples of case students (Eric, Paula and Sofía): a) The student uses a single register of representation: graphic-area (Figure 7); the case of Eric.

The case of Eric. Use of the part-whole subconstruct with successive approaches: divides three bags into four equal parts and two bags into six parts, and therefore, the solution would be that each of the twelve people receives $1 / 4$ and $1 / 6$ of a bag. Eric uses only graphic-area representation (circles). He carries out the cognitive activity of formation.

b) The student uses two registers of representation: graphic-area and symbolic-fraction (Figure 8); the case of Paula.

The case of Paula. Use of the part-whole subconstruct with successive attempts: The student divides three bags into four equal parts and two bags into six parts, and therefore the solution would be that each of the twelve people would receive $1 / 4$ and $1 / 6$ of a bag. She first uses graphic-area representation (circles), and then shifts to a symbolic representation with fractions. Furthermore, the student represents 12 upper-case letters (A, B, C, through to $\mathrm{L}$ ), we assume for each of the 12 people who will receive the divided goods, and she relates them to the portions of the bags, to which she has also assigned letters. She performs the cognitive activities of formation and conversion.

c) The student uses registers of representation: graphic-area, symbolic-fraction and hieroglyphic (Figure 9); the case of Sofía.

The case of Sofía. Use of the part-whole subconstruct with successive approaches: she divides five bags in four parts and two bags in ten equal parts, therefore, the solution would be that each of the twenty people receives $1 / 4$ and $1 / 10$ of a bag. First, she uses the graphic-area representation (rectangles); then, she changes to a symbolic representation with fractional numbers and, lastly, she changes to a hieroglyphic 

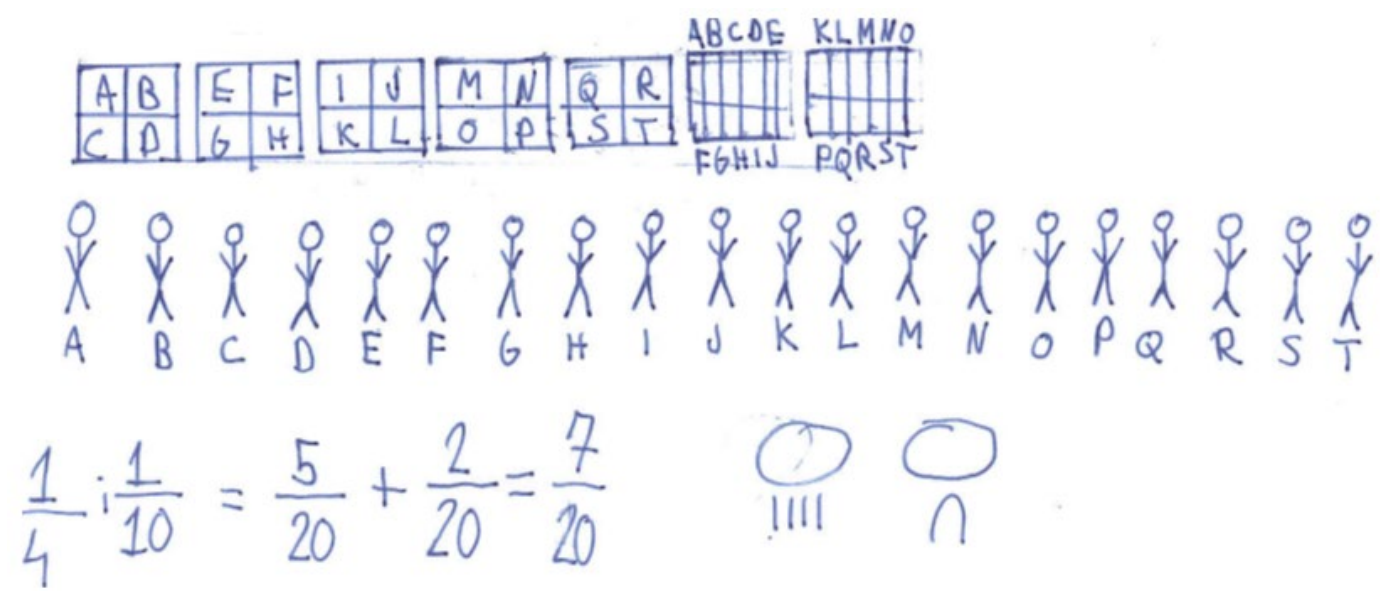

Figure 9. Fragment from Sofía's response in the phase of applying the new knowledge

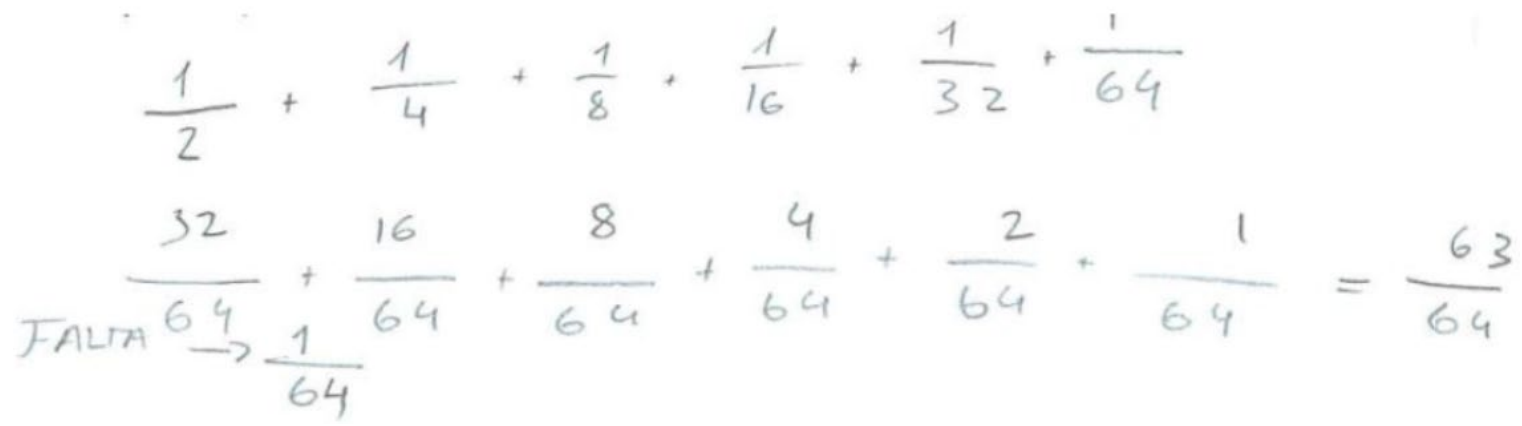

Figure 10. Fragment of Roc's response in the phase of reconstructing the unit

representation. Additionally, the student draws the twenty people receiving a portion, identifying them with upper case letters $(\mathrm{A}, \mathrm{B}, \mathrm{C}, \ldots, \mathrm{T})$ and relates them to the portions of the bags which are also assigned the letters that correspond to each of the people. Likewise, she checks that the sum of the unit fractions $1 / 4$ and $1 / 10$ correspond to the breakdown of the fraction $7 / 20$. She carries out the cognitive activities of formation, treatment and conversion.

iii) In the phase of reconstructing the unit, the responses were classified according to whether the students justified that the sum of the fractions that appeared in the problem was different to the unit, using symbolic representation with fractional numbers, or using graphic-area representation. Responses related to how to complete the Eye of Horus were also considered. The direct part-whole meaning was used in all the answers of the reconstruction phase of the unit; likewise, the register of representation used was symbolic fraction. They perform cognitive activities of formation and treatment. No student explained that the Eye of Horus could be solved (i.e., that the whole could be determined) with Egyptian fractions by adding infinite different unit fractions.

In the responses of the phase of reconstructing the unit we only found the following case which we illustrate with an analysis example:
Solitary case: the sum of fractions that appeared in the problem with symbolic representation with fractional numbers to check if it was different from the unit (Figure 10): the case of Roc.

The case of Roc. The student carries out the sum of all the fractions in the problem using symbolic representation with fractional numbers, obtaining 63/64 as a result; in addition, he indicates that $1 / 64$ is missing. He performed the cognitive activities of formation, treatment and conversion.

\section{RESULTS}

\section{Exploration Phase}

In the exploration phase, the students had to distribute three bags equally among four people and associate their response with the Egyptian fractions, as shown in the directions for the activity.

\section{Solving the division activity}

Eighty-one percent of the students (78 out of 96) were able to do the division correctly, while $19 \%$ (18 out of 96) could not solve the task. Table 2 shows a summary of the results. 
Table 2. Results of the students who carried out the division correctly $(n=78)$ in the exploration phase, by subconstructs and registers of representation used

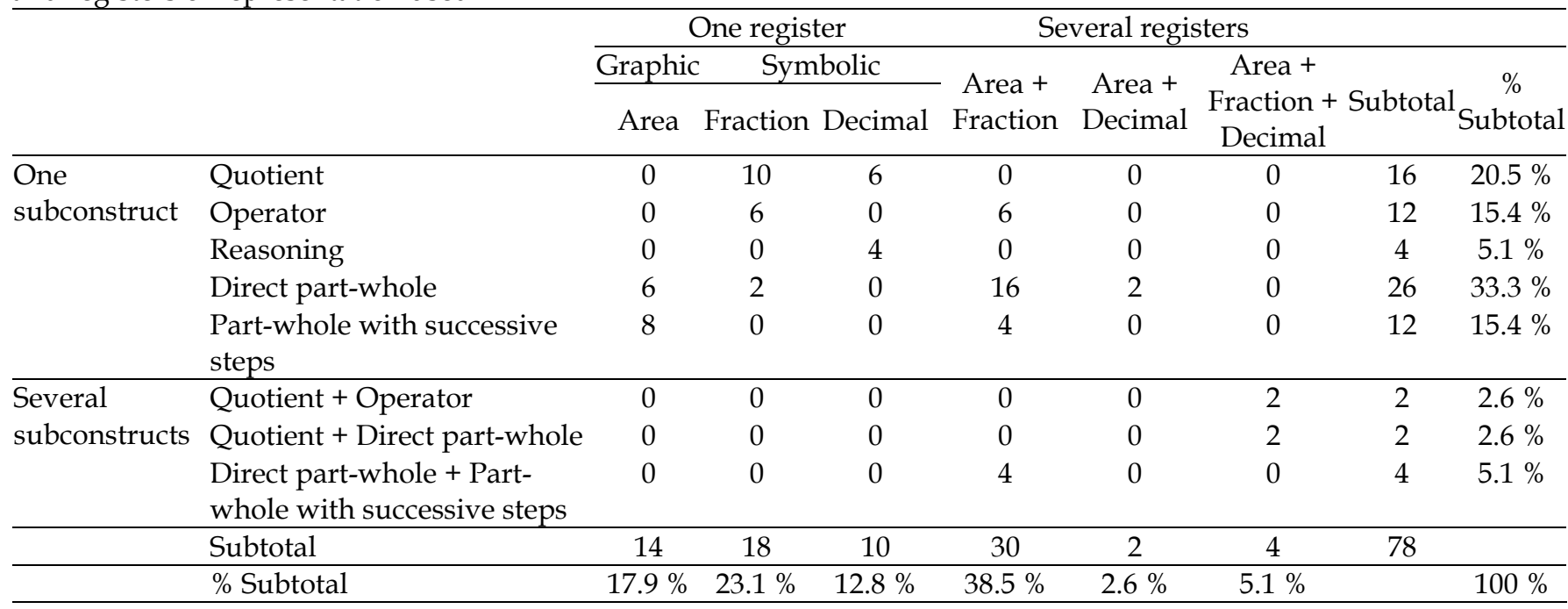
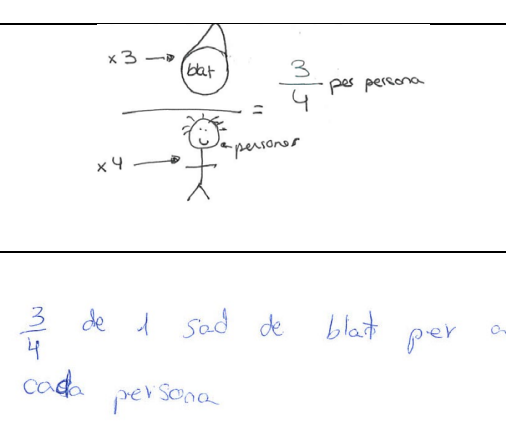

(a) Fragment from Paula's response. Transcription: " $\frac{x 3 \rightarrow \text { wheat }}{x 4 \rightarrow \text { persons }}=\frac{3}{4}$ per person". Subconstruct: quotient.

(b) Fragment from Pol's response. Transcription: “3/4 of 1 bag of wheat for each person". Subconstruct: operator.

(c) Fragment of Irene's response. Transcription: "And each one 1/0.75 1/0.75 $1 / 0.75$ ". Although we think that the correct response should be 0.75 of one bag to 1 person, in other words $0.75 / 1$; in this case, although the student does not specify it, we think that she may have inverted the ratio, interpreting 1 person to 0.75 bags, and as such we consider the response to be valid. Subconstruct: ratio.

(d) Fragment from Carla's response. Subconstruct: direct part-whole.

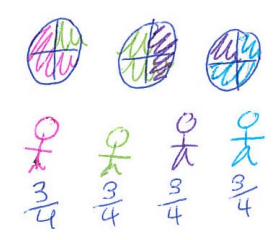

(e) Fragment from Bruna's response. Transcription: “3 bags between 4

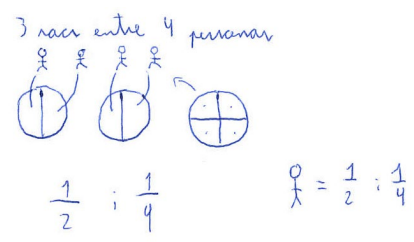
people". Subconstruct: part-whole with successive approaches.

Figure 11. Fragments from the student's responses in the exploration phase, in which evidence is shown of the use of subconstructs of the fraction concept in their solutions, as well as with percentages: quotient (a), operator (b), ratio (c), direct part-whole (d) and part-whole with successive approaches (e)

i) Subconstructs: apart from the measure subconstruct, we identified evidence that the students used the other subconstructs in their solutions: quotient, ratio, direct part-whole and part-whole with successive approaches.

In Figure 11, we show examples of how the students used each subconstruct. 


\section{Percentage of use of subconstructs}

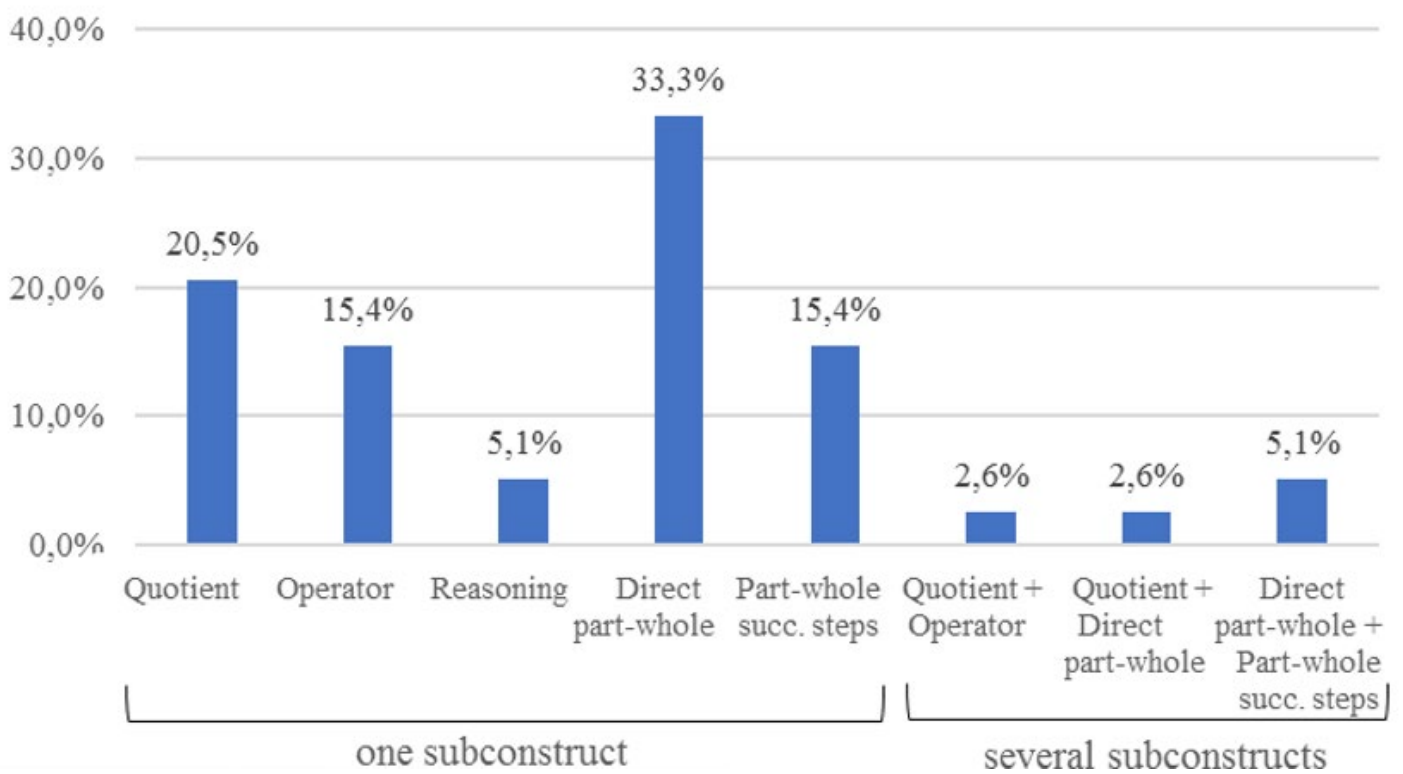

Figure 12. Percentage of use of each subconstruct in the exploration phase

\section{Use of registers of representation in percentages}

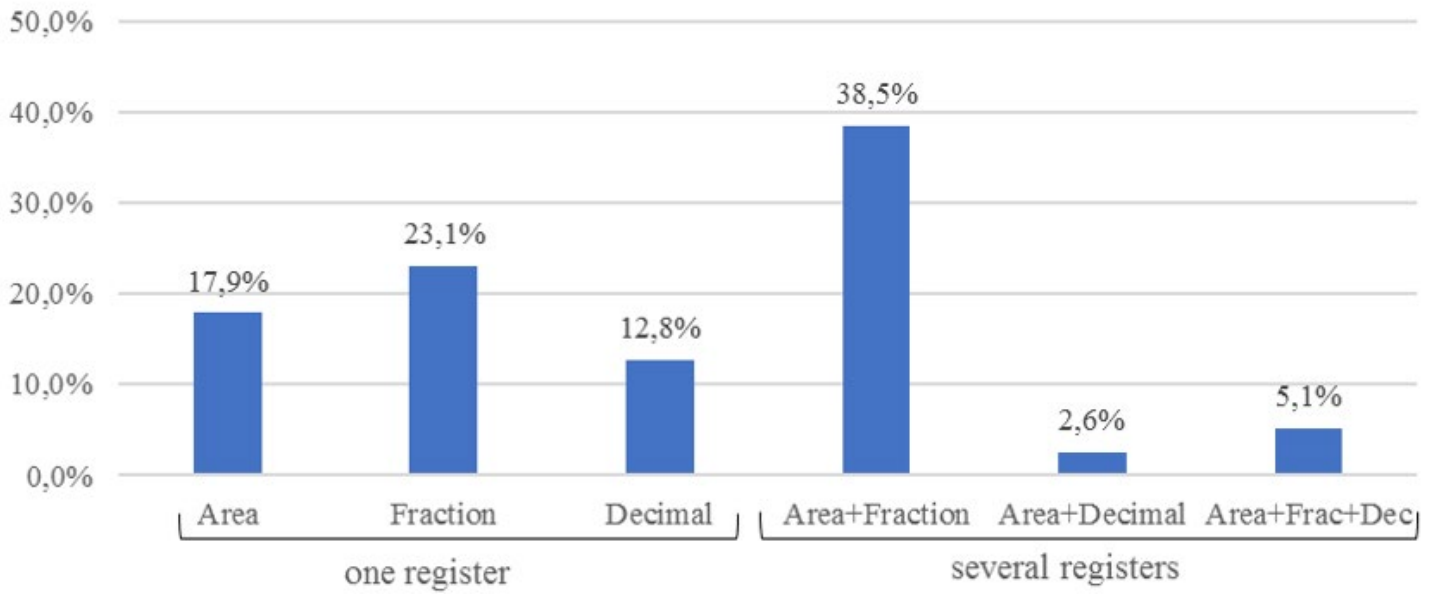

Figure 13. Use of each register of representation in percentages in the exploration phase

According to these results (Table 2), of the students who correctly performed the distribution, $90 \%$ (70 out of 78) used only one subconstruct, while $10 \%$ (8 out of 78 ) used two subconstructs in their solution. In the graph in Figure 12 we show, of the students who only used one subconstruct and various subconstructs, the percentages of use in each of these.

According to the data for Figure 12, of the students who made use of only one subconstruct to solve the distribution in the exploration phase, the most used subconstruct was direct part-whole (33,3\%, 26 out of 78), while the measure subconstruct was not used by any student. With regard to the other subconstructs, the percentages obtained were quotient $20,5 \%$ (16 out of 78 ), operator $15,4 \%$ (12 out of 78$)$, part-whole with successive steps $15,4 \%$ (12 out of 78) and reasoning 5,1 $\%$ (4 out of 78). Similarly, of the students who made use of two subconstructs to solve the distribution in the exploration phase, the most used subconstructs were direct part-whole and part-whole with successive approaches $(5,1 \%, 4$ out of 78$)$, while quotient + operator and quotient + direct part-whole were used by $2,6 \%$ of the students ( 2 out of 78) in both cases.

ii) Representations: according to our results (Table 2), of the students who performed the division correctly, $53.8 \%$ (42 out of 78 ) used a single register of representation (mostly symbolic), while $46.2 \%$ (36 out of 78 ) used several: two (mostly area + fraction) or three registers of representation in their solution. The graphs in Figure 13 show the percentages of students who used each register of representation, divided into those who used just one and those who used more than one.

Consequently, of the students who used only one register of representation, we find a clear predominance of the symbolic system of representation, which accounted for $35,9 \%$ ( 28 out of 78 ), while the graphic 
system of representation was used by $17,9 \%$ (14 out of 78). The $67 \%$ of students who used the symbolic system of representation can be broken down into $23,1 \%$ (18 out of 78 ) who used the fraction register of representation and $12,1 \%$ (10 out of 78 ) who used the decimal register of representation. No evidence was found for use of the percentage register of representation. On the other hand, all the students who used the graphic system of representation did so with the area register of representation, while none used the length and set registers.

Similarly, of the students who used several registers of representation, the two registers used simultaneously with most frequency were area + fraction with 38,5\% (30 out of 78), while area + decimal was used by 2,6\% (2 out of 78 ). Similarly, 5,1\% (6 out of 78) used three registers: area + fraction + decimal.

We also see the use of several registers of representation according to the subconstructs used (Table 2), and distinguish the following cases:

- Use of a single subconstruct (70 out of 78)

- Quotient (16 out of 70): All the students (100\%) used a single symbolic register of representation, $63 \%$ (10 out of 16) used the fraction register and $37 \%$ (6 out of 16) the decimal register. None used several registers simultaneously, and none used graphic representation.

- Operator (12 out of 70): 50 \% (6 out of 12) used a single symbolic register of representation, fraction, while the other $50 \%$ (6 out of 12) used several registers simultaneously: the graphic representation area + the symbolic representation fraction.

- Reasoning (4 out of 70): All the students (100\%) used a single symbolic register of representation, decimal. None used several registers simultaneously, and none used graphic representation.

- Direct part-whole (26 out of 70): 31 \% (8 out of 26) used a single symbolic register of representation, 6 used the graphic representation area and 2 used the symbolic representation fraction. $69 \%$ percent (18 out of 26) used several registers simultaneously, 16 the graphic representation area + the symbolic representation fraction, and 2 the graphic representation area + the symbolic representation decimal.

- Part-whole with successive steps (12 out of 70): 67 $\%$ (8 out of 12) used a single graphic register of representation, area, and $33 \%$ (4 out of 12) used several registers simultaneously: the graphic representation area + the symbolic representation fraction.
- Use of several subconstructs (8 out of 78)

- Quotient + operator (2 out of 8): All students used several registers simultaneously, i.e., the graphic representation area + the symbolic representation fraction + the symbolic representation decimal.

- Quotient + Direct part-whole (2 out of 8): All students used several registers simultaneously, i.e., the graphic representation area + the symbolic representation fraction + the symbolic representation decimal.

- Direct part-whole + Part-whole with successive steps (4 out of 8): All students used several registers simultaneously, i.e., the graphic representation area + the symbolic representation fraction.

\section{Interpretation of Egyptian fractions as a solution to the problem}

Eighty-three percent of students (80 out of 96) shifted from hieroglyphic representation (the Egyptian fractions shown in the problem) to another register of representation, including both those who managed to solve the division and those who did not. In all cases, they used conversion from the hieroglyphic register to the symbolic register fraction. However, of the students who made this shift in representation from the hieroglyphic register to the symbolic register fraction and who also solved the division, only 16 were capable of relating the Egyptian fractions shown in the problem to their own solution; that is, only $17 \%$ of the students (16 out of 96) interpreted the Egyptian fractions as the solution to the problem.

All 16 students who were capable of relating the Egyptian fractions shown in the problem to their own solutions used the part-whole subconstruct with successive steps, and there is no evidence of this with the other subconstructs. That is, all the students who used the part-whole subconstruct with successive steps (the 12 who used a single subconstruct and the 4 who used several subconstructs) interpreted the Egyptian fractions as the solution.

As regards the results of the exploration phase, using a single register of representation is more common in the division activity than using several of them, with the use of symbolic representation (register with fraction) predominating. On the other hand, even though the majority of students made a conversion from the hieroglyphic register to the symbolic fraction register, very few students interpreted the Egyptian fractions as the solution to the problem. Therefore, we can assert that in the exploration phase, the cognitive activity of formation. 


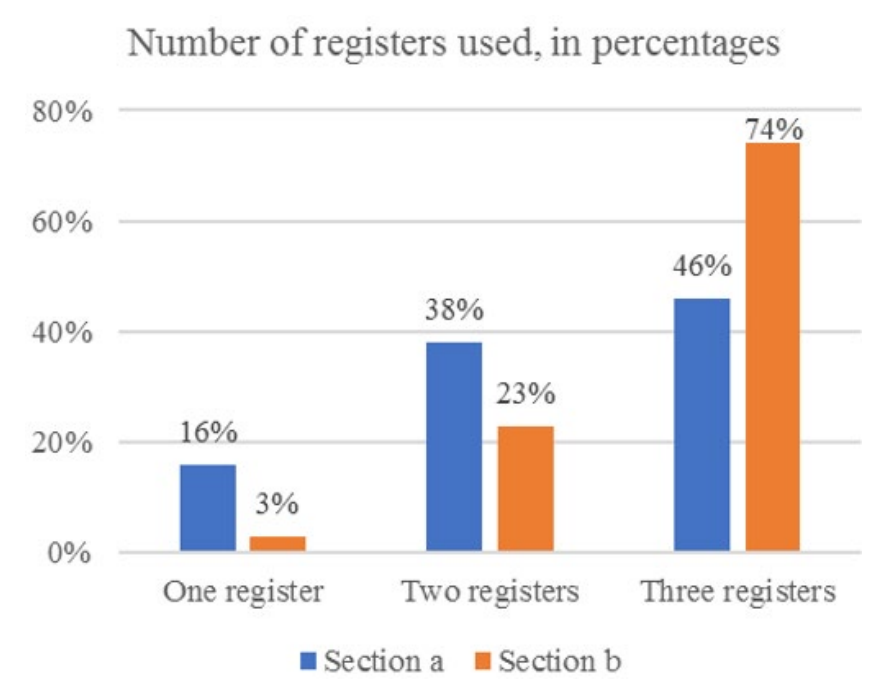

Figure 14. Number registers of representation used, in percentages, in in the section $a$ and the section $b$ of the applying new knowledge phase

\section{Phase of Applying New Knowledge}

The first section, when the students had to distribute 5 bags of flour among 12 people and express the result in Egyptian fractions, was correctly solved by 77 \% (74 out of 96); similarly, the second part, which consisted of dividing 7 bags of flour among 20 people, was correctly solved by $73 \%$ (70 out of 96 ).

In the written productions we find that the breakdown of the initial fractions took place as follows:

- Section a: $92 \%$ (68 out of 74 ) used the breakdown: $5 / 12=1 / 4+1 / 6$; and $8 \%(6$ out of 74$)$ used the breakdown: $5 / 12=1 / 3+1 / 12$; in section a, we did not find any student who in their response did either of these breakdowns simultaneously; nor did any of them indicate that various breakdowns could be performed for one same fraction.

- Section b: $100 \%$ used the breakdown $7 / 20=1 / 4$ $+1 / 10$

All the solutions used a single subconstruct only (100 $\%)$, namely, part-whole with successive steps. The graph in Figure 14 shows the number of registers of representation used by the students in the section a and the section $b$, in percentages, with a predominant use of three registers of representation: graphic-area, symbolicfraction and hieroglyphic.

To expand the information shown in Figure 14, we list below the number of registers of representation used (in percentages) and their characteristics. These reveal three distinct cases:

a) Use of a single register of representation: graphicarea.

$$
\begin{aligned}
& \text { - Section a: } 16 \% \text { (12 out of } 74) \\
& \text { - Section b: } 3 \% \text { (2 out of } 70)
\end{aligned}
$$

b) Use of two registers of representation: graphic-area and symbolic-fraction
- Section a: $38 \%$ (28 out of 74 )

- Section b: $23 \%$ (16 out of 70 )

c) Use of three registers of representation: graphicarea, symbolic-fraction and hieroglyphic

- Section a: $46 \%$ (34 out of 74)

- Section b: $74 \%$ (52 out of 70)

According to the results of the applying-newknowledge phase, using several registers of representation is significantly more common than using a single register, with a predominance of three registers of representation, that is, graphic-area, symbolic-fraction and hieroglyphic. Additionally, we can state that in the applying-new-knowledge phase, most cognitive activities were those of formation and conversion.

\section{Phase of Reconstructing the Unit}

The fractions in the problem were added-up correctly by $57 \%$ of the students (54 out of 96 ) using only symbolic representation with fractions. With regard to the answers on how the Eye of Horus could be made whole, $48 \%$ (26 out of 54 ) of the students who tackled this problem stated that $1 / 64$ had to be added to make the eye whole.

According to these results, $27 \%$ (26 out of 96) of the students were capable of reconstructing the whole based on different fractions through adding (treatment activity) and noticing that $1 / 64$ was needed to complete Horus's eye.

According to the results of the reconstructing-thewhole phase, only symbolic representation with fractions was used to add the fractions. No student stated how the Eye of Horus could be made whole by adding infinite distinct fractions. In this sense, we can assert that most of the cognitive activities were formation and treatment.

\section{DISCUSSION AND CONCLUSION}

Our results confirm that indicated by Lamon (2020), with regard to the fraction concept being frequently introduced through the part-whole subconstruct. This limited use of the possible meanings of the fraction may indicate a lack of knowledge of the rest of the meanings, which reduces the option of the students to obtain alternative solutions to a problem. In this respect, in relation to the work by Ribeiro, Mellone and Jakobsen (2016), which describes the difficulty of the future teachers to abandon their own space of solutions and broaden their reasoning to alternative approaches to the same problem, it highlights the need for teacher training to focus on the development of the interpretative knowledge of teachers, taking into account the alternative knowledge of the students, and their different ways of reasoning and representations. 
In relation to the characteristics of the representations used by the students to show a fraction in the equal share tasks, in our results we find that in the division activity in the exploration phase, the use of a single register of representation prevails over the use of several registers, particularly the use of symbolic representation with fractions. However, in the applying-new-knowledge phase, the use of several registers of representation is more prevalent than the use of a single register, with the use of three registers of representation being predominant, namely, graphic-area, symbolic-fraction and hieroglyphic. Finally, in the reconstructing-thewhole phase, only symbolic representation with fractions was used to add the fractions. This absence of conversion activities in the reconstructing-the-whole phase may be explained by the fact that treatment determines the relevance of best register when applying rules of addition.

In the exploration phase, students carried out the equal-sharing problem using certain registers of representation according to the subconstructs used. Of the students who used a single construct, $100 \%$ of those using the quotient subconstruct used a single symbolic register of representation $(63 \%$ using the fraction register and $37 \%$ using the decimal register). Similarly, $100 \%$ of those who used the reasoning subconstruct used a single symbolic register of representation, namely, decimal. In contrast, of those who used the operator subconstruct, $50 \%$ used a single register of representation (symbolic fraction) and the other $50 \%$ used several registers simultaneously (graphic representation, area + symbolic representation, fraction). However, those who used the direct part-whole subconstruct tended to use several registers simultaneously $(69 \%$, with graphic representation area + symbolic representation), unlike those who used the part-whole with successive steps subconstruct, who tended to use a single register $(67 \%$, with the graphic representation area). All the students who used several subconstructs used several registers simultaneously (graphic representation + symbolic representation). Based on this information, we can deduce that there is a relationship between the subconstruct used and the representation chosen.

In relation to how these representations indicate students' knowledge of the distinct subconstructs of fractions, it should be highlighted that, according to our results (Figure 13), in the exploration phase the 53,8\% use of a single register of representation is slightly higher than the use of several registers $(46,2 \%$, two or three registers); while conversely, in the applying-newknowledge phase (Figure 14), the use of several registers of representation is significantly higher (84 \% and $97 \%$ in the section a and section $b$, respectively) than the use of a single register $(16 \%$ and $3 \%$ in the section a and section $b$, respectively). That is, in the exploration phase, cognitive activity of formation predominated; while in the applying-new-knowledge phase, which was carried out after the whole group had shared their distinct proposed solutions to the previous activity, cognitive activities of formation and conversion were the majority. On the other hand, in the reconstructing-the-whole phase, most cognitive activities were formation and treatment (adding fractions); furthermore, none of the students explained how the Eye of Horus could be solved with Egyptian fractions (adding infinite different unit fractions).

Increase in the use of registers of representation between the exploration phase and the applying-newknowledge phase is equivalent to an increase in the external transformation of registers, which would reveal the cognitive activity of conversion (Duval, 2006). In this sense, the students who used several representations needed to coordinate several different registers of representation, which according to Duval (1993) is necessary to gain a conceptual understanding of the mathematical objects. The fact that the students managed to perform a higher number of conversion activities from one register of representation to another might be evidence of better internal coordination among the distinct systems of semiotic representation, which they are able to choose and use. Transitioning between registers of representation in different contexts could involve mobilizing different meanings of the fraction articulated in each phase. Therefore, in accordance with Duval (2000), this improvement in coordination could be interpreted as proof of the development of students' conceptual understanding between the exploration phase and the applying-new-knowledge phase.

As regards students who were able to relate their solution to Egyptian fractions, interpreting them as a solution to the problem, we observed in our results that this only occurred with those students who used the part-whole subconstruct with successive steps. This leads us to think that, in tasks involving equal sharing, the use of the part-whole subconstruct with successive approaches is an intuitive strategy for students, reinforcing hypothesis that these distributions were initially solved in Ancient Egypt using successive trial and error approaches (Eves, 1969; Furinghetti \& Radford, 2002).

The fact that the students used only the part-whole subconstruct with successive steps and graphic-area representation in the applying-new-knowledge phase may be because this activity was carried out after sharing the distinct solutions proposed in the exploration phase; in other words, the students understood that it was the most appropriate solution strategy and therefore their understanding of the problem improved.

As regards the breakdowns obtained from the fractions: $5 / 12=1 / 4+1 / 6$ and $5 / 12=1 / 3+1 / 12$ in section $a$; and $7 / 20=1 / 4+1 / 10$ in section $b$, the hypothesis of a solution by trial and error appears to 


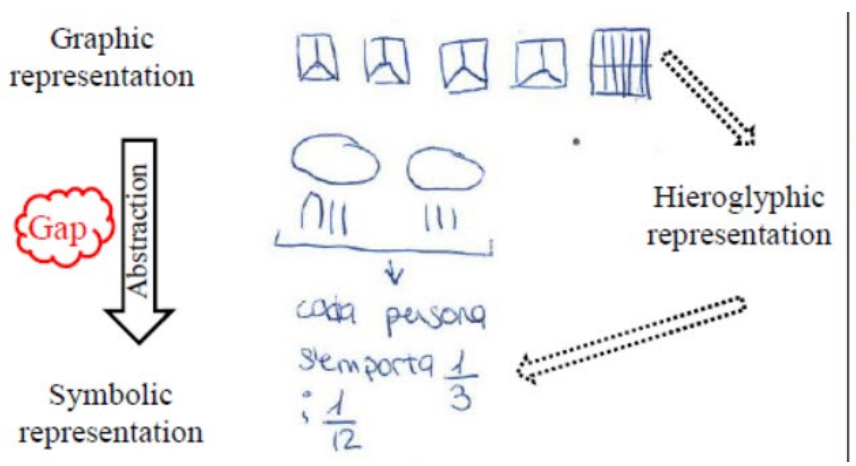

Transcription: "Each person gets $1 / 3$ and $1 / 12$ ". The

hieroglyphic representation establishes a bridge between the graphic representation and the symbolic representation.

Figure 15. Fragment from Nayla's response in the phase of applying new knowledge

corroborate, beginning the approach with the smaller, whole and preferentially even numbers. The preference for the use of even numbers in the first approach could be explained by the use of the graphic-area representation, usually by using rectangle or circle figures, since obtaining a number of even portions in each figure is more straightforward.

In the phase of reconstructing the unit according to our results, $27 \%$ of students were able to reconstruct the unit through an internal transformation of a register, or, in Duval's words (2006), through a cognitive treatment activity. In other words, conceiving a "whole" from the sum of different fractions, justifying that $1 / 64$ was needed to complete the unit by means of a treatment activity.

In the modern interpretation of fractional numbers, they are expressed with a symbolic representation register using two variables (numerator and denominator). One possible explanation for the use of unit fractions in ancient Egypt could be the difficulty of conceiving of a single quantity expressed with more than one variable, interpreting fractional numbers as reciprocals of the integers with a representation register using a single variable. The knowledge of the hieroglyphic representation system used in antiquity by the Egyptian civilisation to express what we currently known as the concept of a fraction can help students to contextualise partition problems and understand that fractions appeared to provide a response to a social reality, as expressions of the quantities obtained when performing equal shares. The activities with Egyptian fractions seem to confirm the results of other studies (Kosheleva \& Lyublinskaya, 2007; Ribeiro, Mellone \& Jakobsen, 2016) which note an improvement in the conceptual understanding of the fractions. It is important that students learn how to solve problems with fractions, using their own informal reasoning strategies; in this regard, the teacher must facilitate the conditions so that students' own intuitive skills emerge and, based on these, help them to consolidate them.

For Freudenthal (1983), the understanding of mathematical knowledge is linked to the mathematical experiences that occur through the situations in which that knowledge is involved. Thus, the intentional use of mathematical knowledge in situations belonging to a particular context accounts for the understanding of what a student uses and how he uses it, and provides specific information about what he understands and how he understands it. The assessment and development of understanding of the fraction demands that mathematical tasks in the classroom cover as many different situations and phenomena as possible, in which the use of different meanings and representations of the fraction makes sense. The students' productions (Figures 4-11) show the use of these different meanings and representations, so we can affirm that the context of Egyptian fractions is an opportunity to promote the construction of the fraction concept, as it establishes the conditions for thinking about mathematics and encourages the development of certain ideas that would not occur in other contexts.

Based on a qualitative analysis of the results, it appears that for some students the transition from the graphic representation to the symbolic representation calls for an abstraction process that becomes a challenge that is difficult to overcome. In the case of the construction of the fraction concept, these difficulties could be reduced through the use of Egyptian fractions, since this hieroglyphic representation seems to lie between graphic and symbolic representations, possessing properties of both (Figure 15). In this way, a bridge could be established to facilitate the transition between the different registers of representation.

When engaging in cognitive activities (Duval, 1993) it is important for teachers to recognize the importance of the proper coordination of distinct registers of representation. This coordination can be improved by tasks that facilitate external transformation among registers to foster a conceptual understanding of fractions. In this way, solving problems that involve equal sharing through Egyptian fractions could be used to effectively manage students' difficulties when they are learning the various meanings (subconstructs) of the concept of fraction, since this would facilitate conversion among the distinct registers of representation.

However, further research is necessary to support this line of work focused on activities which favour coordination between different registers of 
representation which allow for the improvement of students' conceptual understanding. The main limitations of this study consist of the fact that we only analyzed the written production of the students (graphic and symbolic registers), in which there is no need for the use of a specific register of representation to completely define in which activity the students think that they are involved. Furthermore, the individual learning pathways are not analyzed, but rather they are considered as a whole. All of these limitations prevent the cognitive process from being completely described, therefore for its validation it would consequently be important to broaden this study with other aspects which provide us with more information. For example, considering individual learning itineraries that include the analysis of the natural language register, by means of interviews or verbalization produced by pairs of students. In this way, we could recognize the changes produced in the discourse generated by the students, as well as the interaction between the different meanings and representations of the fraction (graphic, symbolic and natural language registers), involved in the resolution of activities with fractions.

Author contributions: All authors have sufficiently contributed to the study, and agreed with the results and conclusions.

Funding: The research presented in this article has been supported and funded by the Spanish Government (Grant no. PID2019104964GB-I00) and the Catalan Governement (Grant no. SGR-2017101).

Declaration of interest: No conflict of interest is declared by authors.

\section{REFERENCES}

Ball D. L. (1993) Halves, pieces, and twoths: constructing representational contexts in teaching fractions. In T. Carpenter, E. Fennema, T. Romberg (Eds.), Rational numbers: An integration of research (pp 157-196). Erlbaum, Hillsdale.

Behr, M., Harel, G., Post, T. \& Lesh, R. (1992). Rational number, ratio and proportion. In D. A. Grows (Ed.), Handbook on research on mathematics teaching and learning (pp. 296-333). Macmillan.

Bentley, K. (2004). Egyptian fractions in Modern Times. Mathematics in School, Jan., 9-10.

Berlinghoff, W. P., \& Gouvea, F. Q. (2004). Math through the ages (Expanded edition). Washington, DC: Mathematical Association of America, Farmington, ME: Oxton House Publishers.

Charalambous, C., Delaney, S., Hsu, H.-Y. \& Mesa, V. (2010). Comparative analysis of the addition and subtraction of fractions in textbooks from three countries. Mathematical Thinking and Learning, 12(2), 117-151. https:/ / doi.org/10.1080/10986060903460070

Clarke, D. M., Roche, A. \& Mitchell, A. (2011). One-toone student interviews provide powerful insights and clear focus for the teaching of fractions in the middle years. In J. Way \& J. Bobis (Eds.), Fractions: Teaching for understanding (pp. 23-32). The Australian Association of Mathematics Teachers.

Cramer, K. A., Post, T. R., \& delMas, R. C. (2002). Initial fraction learning by fourth-and fifth-grade students: A comparison of the effects of using commercial curricula with the effects of using the rational number project curriculum. Journal for Research in Mathematics Education, 33(2), 111-144. https:/ / doi.org/10.2307/749646

Cramer, K., Monson, D., Ahrendt, S., Wyberg, T., Pettis, C., \& Fagerlund, C. (2019). Reconstructing the unit on the number line: Tasks to extend fourth graders' fraction understandings. Investigations in Mathematics Learning, 11(3), 180-194. https:/ / doi.org/10.1080/19477503.2018.1434594

D'Amore, B., Fandiño Pinilla M. I. \& Iori M. (2013). Primi elementi di semiotica. La sua presenza e la sua importanza nel processo di insegnamentoapprendimento della matemática [First elements of semiotics. Its presence and its importance in the teaching-learning process of mathematics]. Pitagora.

Duval, R. (1993). Registres de représentation sémiotique et fonctionnement cognitif de la pensé [Semiotic representation registers and cognitive functioning of thought], Annales de Didactique et de Sciences Cognitives, 5, IREM de Strasbourg, pp. 37-65.

Duval, R. (2000). Basic issues for research in mathematics education. In T. Nakahara \& M. Koyama (Eds.), Proceedings of the 24th Conference of the International Group for the Psychology of Mathematics Education (vol. 1, pp. 55-69), PME.

Duval, R. (2006). A cognitive analysis of problems of comprehension in a learning of mathematics. Educational Studies in Mathematics, 61(1-2), 103-131. https:/ / doi.org/10.1007/s10649-006-0400-z

Empson, S. B., Junk, D., Dominguez, H. \& Turner, E. (2006) Fractions as the coordination of multiplicatively related quantities: a cross-sectional study of children's thinking. Educational Studies in Mathematics 63(1), 1-28. https://doi.org/10.1007/ s10649-005-9000-6

Eves, H. (1969). An introduction to the history of mathematics ( $3 \mathrm{~d}$ ed.). Holt, Rinehart and Winston.

Fauvel, J., \& Gray, J. (Eds.). (1987). The history of mathematics: A reader. Mathematical Assn of Amer.

Fazio, L., \& Siegler, R. S. (2011). Teaching fractions. International Academy of Education. Geneva.

Freudenthal, H. (1983). Didactical phenomenology of mathematical structures (Vol. 1). Springer Science \& Business Media.

Furinghetti, F., \& Radford, L. (2002). Historical conceptual developments and the teaching of 
mathematics: from philogenesis and ontogenesis theory to classroom practice. In Handbook of international research in mathematics education (pp. 643-666). Routledge. https://doi.org/10.4324/ 9781410602541-22

Halliday, M. A. K. (1975). Some aspects of sociolinguistics: Interactions between linguistics and mathematical educations, UNESCO, Copenhague, pp. 64-73.

Jaworski, B., \& Goodchild, S. (2006) Inquiry community in an activity theory frame. In J. Novotná, $H$. Moraová, M. Krátká, \& N. Stehlíková (Eds.), Proceedings of the 30th Conference of the International Group for the Psychology of Mathematics Education (vol. 3, pp. 353-360). PME.

Kaput, J. J. (1987). Representation systems and mathematics. In C. Janvier (Ed.), Problems of representation in the teaching and learning of mathematics (pp. 19-26). Erbaum.

Kieren, T. E. (1993). Rational and fractional numbers: From quotient fields to recursive understanding. In T. P. Carpenter, E. Fennema, \& T. A. Romberg (Eds.), Rational numbers: An integration of research (pp. 49-84). Erlbaum.

Kosheleva, O., \& Lyublinskaya, I. (2007). Using innovative fraction activities as a vehicle for examining conceptual understanding of fraction concepts in pre-service elementary teachers mathematical education. In Proceedings of the 29th Annual Meeting of the North American Chapter of the International Group for the Psychology of Mathematics Education PME-NA (pp. 25-28).

Lamon, S. J. (2007). Rational numbers and proportional reasoning: toward a theoretical framework for research. In F. K. Lester (Ed.), Second handbook of research on mathematics teaching and learning (pp 629667). IAP, Charlotte.

Lamon, S. J. (2020). Teaching fractions and ratios for understanding: Essential content knowledge and instructional strategies for teachers. Routledge. https: / / doi.org/10.4324/9781003008057

Lingard, D. (1999). The history of mathematics: an essential component of the mathematics curriculum at all levels. In Proceedings of the International Conference on Mathematics Education into the 21st Century: Societal Challenges, Issues and Approaches (Vol. III, pp. 38-43), Cairo, Egypt.

Liu, C., Xin, Z., \& Li, X. (2011). The development of Chinese students' understanding of the fraction concepts from fifth to eighth grade, Journal of Mathematics Education, 4(2), 17-34.

MacGregor, N. (2011). A history of the world in 100 objects. Penguin.
NRICH (2020). Egyptian Fractions. https://nrich.maths. org/1173

O'Reilly, D. (1995). Creating Egyptian fractions. The Australian Mathematics Teacher, 51, 10-10.

Oliver, J. (2003). Fractions in ancient Egyptian times. Mathematics in School, 32(1), 14-16.

Pantziara, M., \& Philippou, G. (2012). Levels of students' "conception" of fractions. Educational Studies in mathematics, 79(1), 61-83. https:/ / doi.org/10.1007/ s10649-011-9338-x

Park, J., Güçler, B., \& McCrory, R. (2013). Teaching prospective teachers about fractions: historical and pedagogical perspectives. Educational Studies in Mathematics, 82(3), 455-479. https://doi.org/ 10.1007 / s10649-012-9440-8

Pimm, D. (2002). Symbols and meanings in school mathematics. Routledge. https://doi.org/10.4324/ 9780203428610

Pimm, D. (2014). Unthought knowns. For the Learning of Mathematics, 34(3), 15-16.

Pothier, Y. \& Sawada, D. (1983). Partitioning: The emergence of rational number ideas in young children. Journal for Research in Mathematics Education, 14, 307-317. https://doi.org/10.5951/ jresematheduc.14.5.0307

Ribeiro, M., Mellone, M., \& Jakobsen, A. (2016). Interpreting students' non-standard reasoning: Insights for mathematics teacher education. For the Learning of Mathematics, 36(2), 8-13.

Simon, M. A., Placa, N., Avitzur, A., \& Kara, M. (2018). Promoting a concept of fraction-as-measure: A study of the learning through activity research program. The Journal of Mathematical Behavior, 52, 122-133. https:/ / doi.org/10.1016/j.jmathb.2018.03.004

Steffe, L. P., \& Olive, J. (2009). Children's fractional knowledge. Springer Science \& Business Media. https: / / doi.org/10.1007/978-1-4419-0591-8

Tzur, R. (1999). An integrated study of children's construction of improper fractions and the teacher's role in promoting that learning. Journal for research in mathematics education, 30(4), 390-416. https:/ / doi.org/10.2307/749707

Wilkins, J. L., \& Norton, A. (2018). Learning progression toward a measurement concept of fractions. International journal of STEM education, 5(1), 27. https:/ / doi.org/10.1186/s40594-018-0119-2

Zhang, X., Clements, M. A., \& Ellerton, N. F. (2014). Conceptual mis(understandings) of fractions: From area models to multiple embodiments. Mathematics Education Research Journal, 27, 233-261. https:/ / doi.org/10.1007/s13394-014-0133-8

\section{http://www.ejmste.com}

